\title{
Lagerstroemia for Urban Landscapes in India
}

R.K. Roy

\section{J.S. Khuraijam}

Shilpi Singh
Botanic Garden, CSIR-National Botanical Research Institute, Lucknow - 226001

Botanic Garden, CSIR-National Botanical Research Institute, Lucknow - 226001

\section{ABSTRACT \\ ABSTRACT}

Botanic Garden, CSIR-National Botanical Research Institute, Lucknow - 226001

Landscapes and urban green space plays a critical role for keeping our cities attractive and healthy. Lagestroemias are among the best flowering trees for urban landscapes due to interesting growth, long blooming period and attractive flowers during summer. They grow well in different agro-climatic condition and drought tolerant. These plant species are selected for plantation in central verge, along the road, traffic island and urban green space because they have a capacity to tolerate dust, automobile fumes and have moderate efficiency to absorb air pollution. Moreover, the plants which are used for landscaping should have a good growth habit, flowering and striking flower colour. Lagerstroemia species have all these characters and create attraction while moving through the roads, parks, avenue plantation.

In the present paper, prospect and utility of five species of Lagerstroemia for urban landscaping are discussed.

\section{Introduction}

Plants have the ability to modify the microclimate, especially temperature and humidity factors. Microclimate created in an environment is the result of interaction between plants with other landscape elements. Hence selection of appropriate plants is a very important factor considering the ecological and aesthetic functions (Hidayat, 2010). Selection of trees appropriate for urban landscapes requires far-reaching knowledge of all aspects of selection of plants for landscape. In a large country like India, selection of trees for urban landscapes varied considering the climatic and topo-geographical differences of the urban areas. However, there are several tree species that go well with all the micro-climatic conditions of the cities in India namely, Alstonia scholaris, Azadirachta indica, Delonix regia, Lagestroemias, Magnolia champaca, Polyalthia longifolia, Plumeria sp etc.

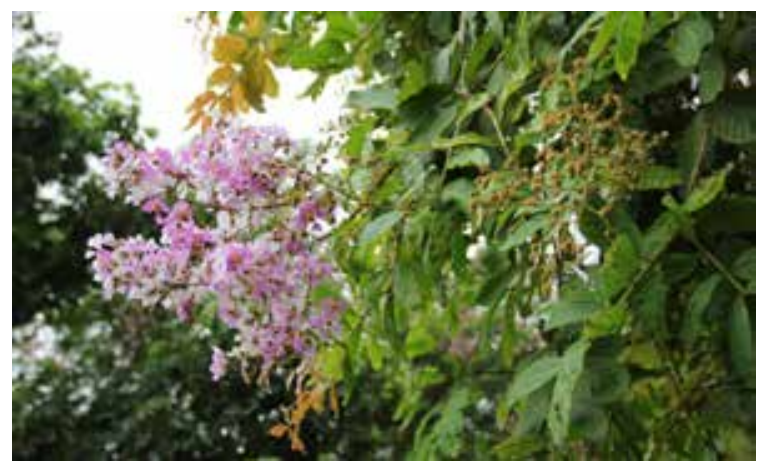

Figure 1. Lagerstroemia speciosa in late summer.

\section{Lagerstroemia as landscape tree}

With long blooming period of beautiful summer flowers and interesting growth characteristics, Lagestroemias are among the best flowering trees for urban landscapes. Lagerstroemia is a genus of some 80 species in the family Lythraceae. They are distributed from India through China, Japan and Malesia to Northern Australia (Pounders et al. 2007, Cabrera, 2004, Furtado \& Srisuko, 1969). Lagestroemias come in wide range of sizes from dwarf shrubs to small trees and grow well in different soil conditions. They are easy to grow, propagate and are drought tolerant. The two most popular species which are cultivated for their showy inflorescences in warmer regions of the world are Lagerstroemia speciosa and L. indica (Egolf \& Andrick, 1978).

\section{Lagerstroemia indica $\mathrm{L}$.}

It is commonly known as 'Crape-Myrtle' and grows naturally in
East Asia and Indian subcontinent. A small deciduous tree or large shrub in habit, Lagestroemia indica grows gracefully either in full sun or under canopy. Leaves are small and oval in shape. Flowers with crimped petals are pink, white or purple in colour.

Crape-Myrtles bloom for 1-2 months during summer and are best suited for border plantings around buildings for summer colour or as mass ground cover plantings in gardens and parks. They can also be planted along the side of the pathways and lawns increasing their beauty and elegance. Several cultivars of Crape-Myrtles are now available in horticultural trade.

Lagestroemia indica are suitable for urban landscaping as they successfully grow in urban areas where air pollution, poor drainage, poor soil and drought are common. Crape Myrtles are almost insect and disease free although there may see aphids from time to time. Spraying on common insecticides will keep away aphids.

\section{Lagerstroemia duperreana Pierre ex Gagnep}

Thorel's Crape Myrtle is a tall tree native of Southeast Asia. Though not very common species, $L$. duperreana is an elegant tree with beautiful flowers that blooms for almost 3 months. Flowers are pink to light purple in colour and fade to white. It has robust trunk with distinctive smooth light brown to grey bark that flakes off in large sections to reveal the new bark developing underneath.

Though Lagerstroemia duperreana has the same potential of other ornamental Lagerstroemias, it is yet to be extensively used in landscaping. Tall trees of Thorel's Crape Myrtle could be shade trees in parks and garden. The adorable trees with its long lasting flowers and distinctive bark could be majestic flowering avenue trees.

It grows well in warm climate, poor soil and tolerant to pests.

\section{Lagerstroemia loudonii Teijsm. \& Binn.}

It is medium size tree originated from Thailand and commonly known as Thai Bungor. Its trunk is not so thick and branches are so slender. It is slightly uncommon in India, blooms almost for 2-3 month. White flowers on full blooms in long inflorescence are very pleasant to see, it gives a scene like a winter season.

This plant used in all types of gardens. The areas along the roads are generally beautified by this specimen tree. It is also use in parks, traffic island, along the boundary of the wall and urban green space. 


\section{Lagerstroemia $x$ lancasteri Hort.}

'Purple Lagerstroemia' is a dwarf tree or a tall shrub with large purple flowers borne at the tip of the branches. It is a hybrid between Lagerstroemia indica 'Candida' and L. matthewsi. This tree was developed by Percy Lancaster, the British Horticulturist in India (1921). This tree is non-spreading, bushy, bark smooth, light brown, free flowering and also slightly fragrant. It blooms profusely during March-April and remaining period in less intensity.

Being dwarf, the species is highly suitable for residential gardens and other small gardens. This tree can also be used in parks, central verge and along the boundary wall for beautifying the landscape and keep the atmosphere free from pollution (Roy, 2013).

Landscapes and urban green space plays a critical for keeping our cities clean and healthy. These plant species are selected for plantation in central verge, along the road, traffic island and urban green space because they have a capacity to tolerate dust, automobile fumes and have moderate efficiency to absorb air pollution. Moreover, the plant which used for landscaping should has a good growth habit, flowering and striking flower colour. Lagerstroemia species have all these types of characters and creates a kind of attraction while moving through the roads, parks, avenue plantation etc.

\section{Lagerstroemia speciosa $\mathrm{L}$.}

'Queen Crape-Myrtle' is the most widely grown Lagerstroemia species. A medium size tree with purple, pink and white flowers, the species is indeed an attraction during summer season. It blooms dramatically for almost 2-4 months making the Queen Crape-Myrtle, the most sought for flowering trees for avenues and gardens. During winter, the leaves turn reddish-brown before shedding.

Green lawn with beds of flowers and row of Queen Crape-Myrtle trees can turn the landscape into a stunning one.

Lagerstroemia speciosa is tolerant of dry soil, pollution and full sun, and has great disease resistance, all positive attributes for plantation in urban locations.

\section{Propagation and growing}

Lagerstroemias are propagated by seed, cuttings or division of rook suckers. Seeds can be easily collected and they germinate readily in few weeks. Propagation by hardwood cuttings are usually done in October-November. For propagation by softwood cuttings is done in May-June. Young plants requires moderate watering and grow fast in well drained soil. Subsequently, when these attain maturity, draw attention by way of their mass blooming and curious flower shape. Lagerstroemias are easy to grow and hardy. Therefore, the species are widely selected for urban landscapes
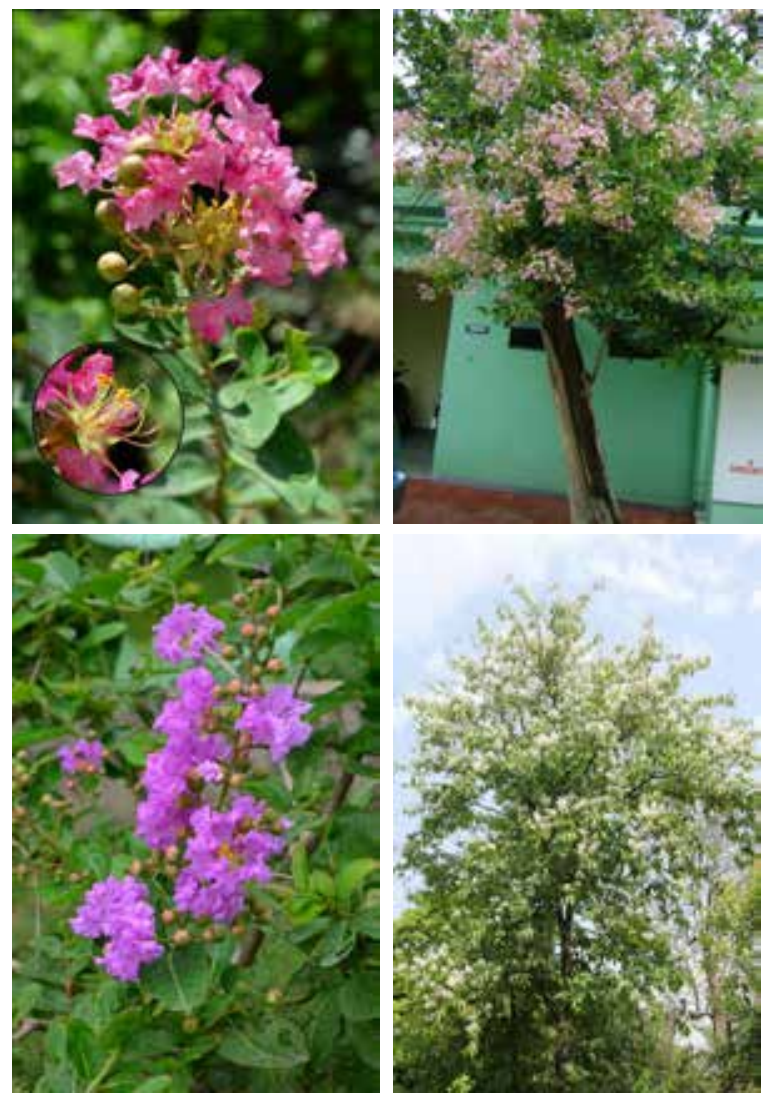

Figure 2. a) Lagerstroemia indica, b) L. duperreana, c) L. lancasteri, and d) L. loudonii

\section{REFERENCE}

Cabrera, R.I. 2004. Evaluating and promoting the cosmopolitan and multi-purpose Lagerstroemia. Acta Hort. 630:177-184. | Datta, R.M. and Jena, P.K. 1977. Preliminary meiotic studies in three species of garden Lagerstroemia (L. flos-reginae Retz., L. lancasteri, a new horticultural variety and L. indica Linn. Var Rose Colour). Indian Agriculturist 21:87-89. | Egolf, D.R. and Andrick, A.0. 1978. The Lrrgersiroeiizin Handbook/Checklist. Am. Assoc. Bot. Gard. 8: Arboreta, Inc. | Furtado, C.X. and Srisuko, M. 1969. A revision of Lagerstroemia L. (Lythraceae). Garden Bul. (Singapore) 24:185-334. | Hidayat, I.W. 2010. The ecological role of trees and their interactions in forming the microclimate amenity of environment. Jurnal BUMI lestari 10(2) 182-190. | Percy-Lancaster, S. 1921. Lagerstroemia. Proceedings of the Agricultural and Horticultural Society of India 20-21. | Pounders, C., Rinehart, T. and Sakhanokho, H. 2007. Evaluation of Interspecific Hybrids between Lagerstroemia indica and L. speciosa. HortScience 42(6): 1317-1322. | Roy, R.K. 2013. Fundamentals of garden designing. New India Publishing Agency, New Delhi | Roy, R.K. 2014. Ornamental trees of India. Pointer Publishers, Jaipur | 